\title{
Meta Analysis: Effect of Mammography Screening on Breast Cancer Mortality
}

\author{
Bening Rahimi Titisari'), Vitri Widyaningsih2), Bhisma Murti ${ }^{1)}$ \\ ${ }^{1)}$ Masters Program in Public Health, Universitas Sebelas Maret \\ ${ }^{2)}$ Faculty of Medicine, Universitas Sebelas Maret
}

\section{ABSTRACT}

Background: Breast cancer is the most common cancer experienced by women in developing and developed countries. One of the early detection of breast cancer is mammography. This study aims to analyze the effect of screening mammography on breast cancer mortality by using a meta-analysis study.

Subjects and Method: This was a systematic review and meta-analysis conducted using PRISMA flow diagrams. Search articles through journal databases including: Google Scholar, PubMed, and BMJ by selecting articles published in 2005-2020. The keywords used are "Mammography" AND "Mortality" AND "Breast Cancer". The inclusion criteria were full text articles with an observational study design, articles in English, multivariate analysis with adjusted Hazard Ratio. Eligible articles were analyzed using the Revman5.3 app.
Results: A meta-analysis of 11 cohort studies showed that screening mammography was 0.65 times lower in breast cancer mortality compared with women who were not screened for mammography $(\mathrm{aHR}=0.65 ; 95 \% \mathrm{CI}=0.54$ to $0.79 ; \mathrm{p}=0.0001)$.).

Conclusion: Mammography screening reduces breast cancer mortality.

Keywords: Mammography Screening, Breast Cancer, Meta-analysis

\section{Correspondence:}

Bening Rahimi Titisari. Masters Program in Public Health, Universitas Sebelas Maret. Jl.Ir. Sutami 36A, Surakarta 57126, Central Java. Email: dr.beningbiru@gmail.com. Mobile: 082194287848.

\section{Cite this as:}

Titisari BR, Widyaningsih V, Murti B (2021). Meta Analysis: Effect of Mammography Screening on Breast Cancer Mortality. J Epidemiol Public Health. 06(01): 148-156. https://doi.org/10.26911/jepublichealth.2021.06.02.02.

\section{(i) (2)} Journal of Maternal and Child Health is licensed under a Creative Commons Attribution-NonCommercial-ShareAlike 4.o International License.

\section{BACKGROUND}

Non-communicable diseases are the largest contributor to death worldwide. The four largest non-communicable diseases are cardiovascular disease, diabetes mellitus, cancer and chronic respiratory disease (Bray et al., 2018). Cancer is the second leading cause of death globally. In 2018, about 9.6 million deaths, or one in six deaths, were caused by cancer (Bray et al., 2018). Breast cancer is the top cancer experienced by women in developing and developed countries (WHO, 2016). The estimated age standard incidence in 2020 for breast cancer is 47.8. Breast cancer also ranks second after lung cancer for an estimated mortality rate of 13.6 (GLOBOCAN, 2020). White and black women have the same chance of developing breast cancer. However, black women have a higher chance of dying from breast cancer (Richardson et al., 2016). Cancer in Indonesia shows a tendency to increase in incidence in recent years. As reported by Riskesdas that there was an increase in cancer prevalence from $1.4 \%$ in 2013 to $1.49 \%$ in 2018 (Riskesdas, 2018). The highest incidence rate for women is breast cancer, which is 42.1 per 100,000 
population with an average death rate of 17 per 100,000 population (Ministry of Health of the Republic of Indonesia, 2019).

The incidence of delays in breast cancer patients conducting an initial examination of health services in Indonesia reaches more than $80 \%$. This results in the incidence of breast cancer being found at an advanced stage. Hospital Information System (SIRS) data shows 60\%-70\% of patients who come to the hospital in advanced stages III and IV (Ministry of Health, 2016). Research shows that early detection of breast cancer has an important role in reducing mortality and improving disease prognosis (Rahimzadeh et al., 2014).

Breast cancer can be prevented if detected early. The most important and useful thing for self-protection from breast cancer is early detection of breast cancer (screening). Diagnosis of breast cancer at an early stage is associated with a reduction in breast cancer mortality and morbidity (Khatib, 2006). Most professional organizations in the United States recommend early detection by mammography with appropriate follow-up for abnormal screening tests (Winters et al., 2017). In a study it was said that the recommendation for mammography could reduce the mortality rate from breast cancer by $28 \%$ (Weedon-Fekjræ et al., 2014).

Several meta-analytical studies on mammography on breast cancer have also been conducted. A meta-analysis of studies conducted from databases from 1966-1993 found that mammography was effective in reducing breast cancer mortality in women aged 50-74 years after seven-nine years of follow-up, regardless of the screening interval or the number of mammographic views per screen. However, in the group of women aged 40-49 years, there was no decrease in breast mortality (Slawson\& Coates, 1995). A meta-analysis conducted using the PubMed/MEDLINE database, OVID, COCHRANE, and the Educational Resources Information Center (ERIC) concluded that mammography screening was effective and reduced breast cancer mortality by $17 \%$ in women aged $39-49$ years (Magnus et al., 2011). A meta-analysis study using a 1995-2006 databases in Australia also stated that there was a $49 \%$ reduction in breast cancer mortality in women undergoing mammography screening (Nickson et al., 2012). A quasi-experimental meta-analysis study suggests that mammography may have an effect on breast cancer mortality in the 50-69 year age range. However, for ages over 70 years, it has not shown a significant effect (Irvin and Kaplan, 2014). A European meta-analysis study by source Pubmed October 2019 said that there was a significant $22 \%$ reduction in breast cancer mortality by invitation to screening, with a relative risk of 0.78 (95\% CI 0.75-0.82), and a significant $33 \%$ reduction with actual attendance at screening $(\mathrm{RR}=0.67,95 \% \mathrm{CI}$ 0.61-0.75) (Dibden et al., 2020).

Various studies have been carried out to see the effect of mammography examination on mortality in breast cancer patients, but the results of the research still do not show consistent results. Further analysis is needed to arrive at a convincing conclusion. Therefore, researchers are interested in examining the effect of mammography examinations on mortality in breast cancer patients.

\section{SUBJECTS AND METHOD}

\section{Study Design}

The study design used in this research is a systematic review and meta-analysis, using PRISMA flow diagram guidelines. Article searches were conducted using journal databases including: PubMed, Google Scholar and BMJ. The keywords used are "mammography" OR "mammography 
screening" AND "mortality" AND "breast cancer".

\section{Inclusion Criteria}

The inclusion criteria were full text articles in 2005-2021 using an observational study design, namely a cohort, articles in English, the analysis used was multivariate with adjusted Hazard Ratio, the research subjects were women aged 40 years, the intervention was screening mammography and the outcome is breast cancer mortality.

\section{Exclusion Criteria}

Exclusion criteria in this study included articles published before 2005 and languages other than English.

\section{Operational Definition of Variable}

In formulating the problem, the researcher here uses PICO. The population is women aged 40 years. Intervention is screening mammography, with comparison that is not screening mammography, and outcomes is breast cancer mortality.

Mammography examination is an imaging modality that uses low energy Xrays specifically for imaging breast tissue which is used as a screening tool to detect early breast cancer in asymptomatic women. Mortality is the permanent loss of all signs of life at any time after live birth, i.e. the loss of life functions after birth, without the possibility of resuscitation.

Breast cancer is a disease in which cells in the breast grow out of control and are diagnosed by radiological examination.

\section{Instrument}

An assessment of the quality of research articles is carried out using the Critical Appraisal Skills Program (CASP) for Cohort Study).

\section{Data Analysis}

The Review Manager application (RevMen 5.3) was used in analyzing the data in this study. The results of data analysis are in the form of effect size values and study heterogeneity which later the results of the data that have been analyzed are interpreted in the form of forest plots and funnel plots.

\section{RESULTS}

Research from primary studies related to the effect of screening mammography on breast cancer mortality consisted of 11 studies originating from 1 study from the Asia, 5 studies from the Europe, and 5 studies from the North America. Figure 1 shows the region of the retrieved articles that fit the inclusion criteria. Furthermore, the researchers conducted an assessment of the quality of the articles and there were 11 cohort study articles. The results show that screening mammography has an effect on breast cancer mortality. The article search was carried out using a database based on the PRISMA flow diagram, which can be seen in Figure 1.

\section{Forest plot}

The forest plot provides a summary of the data entered and gives weights for each study, effect sizes, methods and models used to perform the meta-analysis, confidence intervals used, estimated impact of each study, overall effect estimates, and statistical significance of the analysis. Interpretation of the results of the meta-analysis process can be seen through the forest plot. Figure 2 shows that the results of the analysis in the cohort study, screening mammography examination 0.65 times reduced breast cancer mortality $(\mathrm{aHR}=0.65 ; 95 \% \mathrm{CI}=0.54$ to 0.79$)$ and statistically signifycant $(\mathrm{p}=$ o.001). The heterogeneity of the research data showed $\mathrm{I}^{2}=91 \%$. Therefore, the distribution of data is expressed by heterogeneous (random effect model).
Articles identified through database search $(n=1,326)$
Delete duplicate data $(n=187)$ 
Titisari et al./ Effect of Mammography Screening on Breast Cancer Mortality

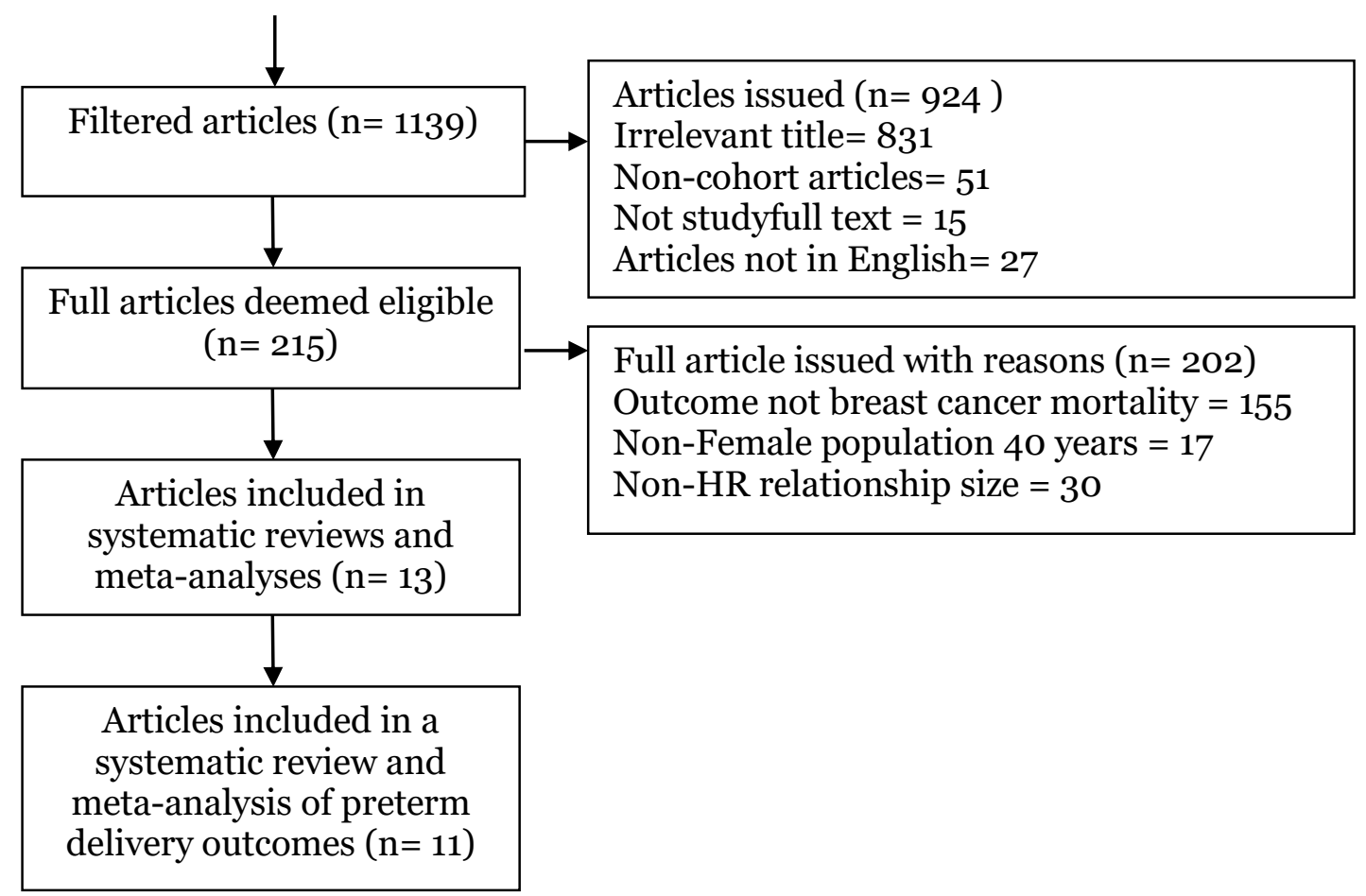

Figure 1. PRISMA flow diagram

\section{Funnel Plot}

A funnel plot is a plot that depicts the approximate size of the effect of each study on the estimate of its accuracy which is usually the standard error.

Based on Figure 3, the cohort study shows a publication bias indicated by the asymmetric distribution of right and left plots where 4 plots are on the right, and 7 plots are on the left. The plot on the left of the graph appears to have a standard error between 0 and 0.4 and the plot on the right has a standard error between 0 and 0.2.

\begin{tabular}{|c|c|c|c|c|c|c|c|c|}
\hline Study or Subgroup & log[Hazard Ratio] & SE & Weight & $\begin{array}{c}\text { Hazard Ratio } \\
\text { IV, Random, } 95 \% \mathrm{CI}\end{array}$ & & $\begin{array}{r}\text { Hazard } \\
\text { IV, Rando }\end{array}$ & $\begin{array}{l}\text { d Ratio } \\
\text { m, } 95 \% \mathrm{Cl}\end{array}$ & \\
\hline anttinen 2006 & -0.1508 & 0.0369 & $11.5 \%$ & $0.86[0.80,0.92]$ & & $=$ & & \\
\hline Chen 2020 & -1.5606 & 0.3785 & $4.3 \%$ & $0.21[0.10,0.44]$ & & & & \\
\hline kaplan 2015 & -0.844 & 0.2374 & $7.0 \%$ & $0.43[0.27,0.68]$ & & & & \\
\hline malmgren 2014 & -0.6931 & 0.2439 & $6.9 \%$ & $0.50[0.31,0.81]$ & & 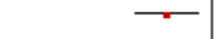 & & \\
\hline Mook 2011 & -0.478 & 0.1098 & $10.3 \%$ & $0.62[0.50,0.77]$ & & $=$ & & \\
\hline narod 2011 & -0.6539 & 0.1736 & $8.6 \%$ & $0.52[0.37,0.73]$ & & - & & \\
\hline paci 2008 & -0.0408 & 0.1125 & $10.2 \%$ & $0.96[0.77,1.20]$ & & & & \\
\hline Sebuødegård 2019 & -0.2231 & 0.0681 & $11.1 \%$ & $0.80[0.70,0.91]$ & & $=$ & & \\
\hline sigurdsson 2013 & -0.7765 & 0.2014 & $7.9 \%$ & $0.46[0.31,0.68]$ & & 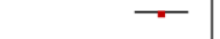 & & \\
\hline Vacek 2015 & 0.1989 & 0.0669 & $11.1 \%$ & $1.22[1.07,1.39]$ & & & $=$ & \\
\hline yen 2016 & -0.5798 & 0.0786 & $10.9 \%$ & $0.56[0.48,0.65]$ & & $=$ & & \\
\hline Total $(95 \% \mathrm{CI})$ & & & $100.0 \%$ & $0.65[0.54,0.79]$ & & $\hat{~}$ & & \\
\hline \multicolumn{5}{|c|}{$\begin{array}{l}\text { Heterogeneity: } \mathrm{Tau}^{2}=0.08 ; \mathrm{Chi}^{2}=108.54, \mathrm{df} \\
\text { Test for overall effect: } Z=4.32(\mathrm{P}<0.0001)\end{array}$} & 0.01 & \begin{tabular}{c|c}
0.1 & 1 \\
mammography
\end{tabular} & $\begin{array}{c}10 \\
\text { no mammography }\end{array}$ & 100 \\
\hline
\end{tabular}

Figure 2. Forest plot of the effect of screening mammography on breast cancer mortality

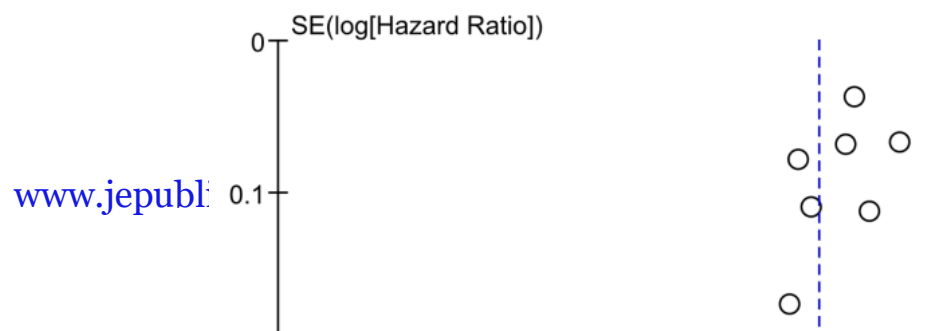




\section{Figure 3. Funnel plot of the effect of screening mammography on breast cancer mortality}

\begin{abstract}
DISCUSSION
This systematic study and meta-analysis discusses the effect of screening mammography on breast cancer mortality. The independent variables were analyzed by women aged 40 years who performed screening mammography. The dependent variable in this study was breast cancer mortality. The results of the primary study conducted showed that the epidemiological study design with a larger sample size, in addition to the demographic characteristics that vary in various countries, will serve as the basis for concluding that women who undergo screening mammography have a statistical effect on cancer mortality breast.

Breast cancer is the most common malignancy in women worldwide. Death from breast cancer is still a global problem, including Indonesia. The high mortality from breast cancer in Indonesia is still a special concern. Most breast cancers detected in Indonesia are in stages III-IV. The delay in breast cancer patients doing examinations, causes high rates of breast
\end{abstract}

cancer morbidity and mortality (Ministry of Health, 2016).

Screening mammography is a specific type of breast imaging that uses low-dose $\mathrm{x}$ rays to detect cancer early - before a woman develops symptoms - when the cancer is most treatable (RadiologyInfo.org, 2019). So far the only breast cancer screening method that has been shown to be effective in an organized population-based program is screening mammography. However, reports on the benefits and harms of screening mammography differ markedly in the context and intensity of screening examined, as well as in the interpretation of the available evidence. The majority of countries that have been able to apply this program are upper middle income countries (WHO, 2014).

Breast self-examination and routine clinical examinations are clinical ways to detect breast cancer early. However, because most breast cancers are not detected early, imaging has an important role (Yunus et al, 2004). Approximately 25-43\% of cancers that are not palpable are detected on 
mammography due to microcalcification (Zeeshan et al, 2018). The benefit of mammography is to detect all types of breast cancer, including invasive ductal cancer and invasive lobular cancer, as a supporting tool in helping doctors to detect small tumors. With early detection through mammography screening, it is hoped that the cancer detected is at an early stage, so that the treatment provided can be maximal. Early stage breast cancer has a good prognosis. (Brodersen et al., 2010; Løberg et al., 2015) (Løberg et al., 2015).

A study compared serial and nonserial screening mammography. The incidence of breast cancer that proved fatal within 10 years of diagnosis was 50\% lower for serial mammography screening participants compared to non-serial mammography screening participants. Participants who attended two of the previous mammography screenings experienced a 29\% reduction in breast cancer deaths compared to patients who attended only one screening. The protection provided by screening mammography does not last long so it is hoped that participants do not miss a single screening because it can increase the risk significantly (Duffy et al, 2021).

Other studies suggest that women who attend screening, and who usually have breast cancer diagnosed at an early stage, benefit significantly more from the advanced therapies available at the time of diagnosis than women who do not attend screening. Detection at an early stage through participation in screening mammography provides a significant reduction in the risk of death from breast cancer when modern adjuvant therapies are available (Duffy et al, 2020).

This study uses previous primary studies that control confounding factors, this can be seen based on the inclusion requirements of the study using multivariate analysis and the statistical results are adjusted hazard ratio (aHR). Confounding factors are mixed estimates of the effects of exposure being studied on the risk of disease by other factors related to exposure and are independent risk factors for the disease under study (Murti, 2018). These eleven research articles have several similarities in controlling for confounding factors. Several confounding factors that have been controlled for include age, tumor characteristics (tumor grade, node status, and tumor stage), ER status and adjuvant therapy. However, only one study included comorbid status as a confounding factor. Estimated association between screening mammography and breast cancer mortality was processed using the RevMan 5.3 application.

\section{Effect of Mammography Screening on Breast Cancer Mortality}

There are 11 research articles with cohort studies which are the source of metaanalysis of the effect of screening mammography examination on breast cancer mortality. The results of the forest plot of research articles with an observational cohort design showed that screening mammography was 0.65 times lower cancer mortality compared to not screening mammography and the results were statistically significant $(\mathrm{aHR}=0.65 ; 95 \% \mathrm{CI}=0.54$ to $0.79 ; \mathrm{p}=0.001)$.

The results of the analysis of 11 articles regarding the effect of screening mammography on breast cancer mortality reported that there was a high heterogeneity between experiments $\left(\mathrm{I}^{2}=91 \%\right.$; $\left.\mathrm{p}<0.001\right)$ so the Random Effect Model (REM) was used population. In these 11 primary research articles, there is a fairly large range of samples (243-856,524 samples). Another difference is in the age criteria. The age used in the 11 primary articles is from the age of 40 to 82 years. Another difference is that 
there is an intervention interval in each study, there are three studies that screen every two years, one study screens every year, and seven studies do not mention how many times the screening is done.

The systematic review and metaanalysis in this study aims to increase the generalizability of the findings and obtain convincing conclusions from the results of various similar studies regarding the effect of screening mammography on breast cancer mortality. In addition, a systematic review and meta-analysis in this study also uses research that controls confounding factors that can be seen from the research inclusion criteria, namely using a cohort design and the statistical results reported are Adjusted Hazard Ratio. Even so, there are still confounding factors from several primary studies that can influence the actual effect relationship.

(Beau et al., 2018) in their study stated that screening mammography has a clear long-term beneficial effect with a 20\% reduction in breast cancer mortality in the invited population. However, this effect was only potential in women who were invited to mammography screening. Meanwhile, for women whose age has passed the screening period and diagnosed with breast cancer, the benefits obtained from screening mammography are very small (age-adjusted rate ratio $=0.80 ; 95 \% \mathrm{CI} ; 0.71-0.90)$.

Research conducted by (Taylor et al., 2004) found that reductions in breast cancer mortality in New South Wales went hand in hand with population screening. On the regression coefficient, at $70 \%$ biennial screening rate was associated with $32 \%$ lower mortality from breast cancer compared with no screening. At the municipal level, it was found that more screening was carried out in addition to other treatments such as breast selfexamination and breast examination by a doctor. Factors associated with reduced mortality include age, geography, breast cancer incidence, and socioeconomic level.

In a study conducted by (Irvin et al., 2020) comparing interval breast cancer with breast cancer detected during mammography. The results of this study indicated that interval breast cancer had a higher risk of death than breast cancer detected on mammography (aHR $=1.64$; 95\% CI, 1.14-2.34). Interval breast cancer diagnosed within 1 year with a previous negative mammogram, had a higher proportion of invasive lobular carcinoma than breast cancer detected through screening. Mammography is known to be less sensitive for identifying lobular cancer, partly due to the fact that lobular tumor cells spread diffusely, and the lack of mammographic evidence of calcification due to possible loss of E-cadherin calcium-dependent transmembrane protein.

However, in a study conducted by (Autier et al., 2012) stated that breast cancer mortality statistics in Sweden are consistent with several studies that show limited or no impact of screening on breast mortality. In this study, the investigators could not consider the effect of risk factors on breast mortality that could mask the mortality effect of screening. In addition, differences in the availability of adjuvant therapy in each region also affect breast cancer mortality.

Ultrasonography (USG) and mammography are standard screening tools to detect and evaluate breast cancer. A study compared the sensitivity and specificity between ultrasound and mammography and stated that the sensitivity and specificity of mammography were $73 \%$ and $55 \%$, and the false-negative rate was $17.27 \%$, respectively. Mammography is more effective in women aged 50 years because the older a woman is, 
the lower the breast density (Haghighi et al, 2017) (Luczynska et al, 2016).

Ultrasound can tell whether a lump is a solid mass or a fluid-filled cyst, but a large number of breast cancers are difficult to see using ultrasound because it is difficult to distinguish between fatty breast tissue and cancerous tissue (Mehnati and Tirtash, 2015). Ultrasound is recommended over mammography for women aged 45 years and younger and women with dense breasts. Dense fibrous glandular tissue is the most important inherent limitation of mammography in the diagnosis of breast cancer. Bilateral whole-breast ultrasound can be an effective adjunct imaging examination in the evaluation of women with dense breast tissue on mammography (Haghighi et al, 2017).

\section{AUTHOR CONTRIBUTION}

Bening Rahimi Titisari is the main researcher who chooses the topic, conducts a search for data collection in this study. Vitri Widyaningsih and Bhisma Murti conducted data analysis and review of research documents.

\section{FUNDING AND SPONSORSHIP}

This study is self-funded.

\section{CONFLICT OF INTEREST}

There is no conflict of interest in this study.

\section{ACKNOWLEDGEMENT}

The author would like to thank all those who have helped in the preparation of this article and also thank the database providers PubMed, BMJ, and Google Scholar.

\section{REFERENCES}

Autier P, Koechlin A, Smans M, Vatten L, Boniol M (2012). Mammography screening and breast cancer mortality in Sweden. J Natl Cancer Inst. 104
(14): 1080-1093. https://doi.org/10.1093/jnci/djs272.

Beau AB, Andersen PK, Vejborg I, Lynge E (2018). Limitations in the effect of screening on breast cancer mortality. $\mathrm{J}$ Clin Oncol. 36(30): 2988-2994. https://doi.org/10.1200/JCO.2018.78 .0270 .

Bray F, Ferlay J, Soerjomataram I, Siegel R L, Torre LA, Jemal A (2018). Global cancer statistics 2018: GLOBOCAN estimates of incidence and mortality worldwide for 36 cancers in 185 countries. CA Cancer J Clin. 68(6): 394-424. https://doi.org/10.3322/caac.21492.

Brodersen J, Jørgensen KJ, Gøtzsche PC (2010). The benefits and harms of screening for cancer with a focus on breast screening. Polskie Archiwum Medycyny Wewnetrznej, 120(3): 8994. https://doi.org/10.20452/pamw.895.

Dibden A, Offman J, Duffy SW, Gabe R (2020). Worldwide review and metaanalysis of cohort studies measuring the effect of mammography screening programmes on incidence-based breast cancer mortality. Cancers. 12(4). https://doi.org/10.3390/cancers12040976.

Duffy SW, Tabár L, Yen AM, Dean PB, Smith $\mathrm{RA}$, Jonsson $\mathrm{H}$, Törnberg $\mathrm{S}$, et al. (2021). Beneficial effect of consecutive screening mammography examinations on mortality from breast cancer: A prospective study. Radiology. 299(3): 541-547. https://doi.org/10.1148/radiol.2021203935.

Duffy SW, Tabár L, Yen AM, Dean PB, Smith $\mathrm{RA}$, Jonsson $\mathrm{H}$, Törnberg $\mathrm{S}$, et al. (2020). Mammography screening reduces rates of advanced and fatal breast cancers: Results in 549,091 women. Cancer, 126(13): 2971-2979. 
Titisari et al./ Effect of Mammography Screening on Breast Cancer Mortality

https://doi.org/10.1002/cncr.32859

GLOBOCAN (2020). Estimated age-standardized incidence rates (World) in 2018, all cancers, both sexes, all ages. World Health Organization (WHO), 2018. https://gco.iarc.fr/today/online-analysis-map? $\mathrm{v}=2018 \& \operatorname{mode}=$ population\&mode population $=$ continen ts\&population $=900 \&$ populations $=90$ o\&key $=$ asr\&sex $=0 \&$ cancer $=39 \&$ type $=$ o\&statistic $=5 \&$ prevalence $=0 \&$ populat ion group $=0 \& a g e$ group $\% 5 \mathrm{~B} \% 5 \mathrm{D}=$ o\&ages group $\% 5 \mathrm{~B} \% 5 \mathrm{D}=17 \& \mathrm{nb}$ item $\underline{\mathrm{s}=5 \& g r 0}$

Haghighi F, Naseh G, Mohammadifard M, Abdollahi N. (2017). Comparison of mammography and ultrasonography findings with pathology results in patients with breast cancer in Birjand, Iran. Electron Physician. 2017;9(10):5494-5498. Published 2017 Oct 25. doi:10.19082/5494

Irvin VL, Kaplan RM (2014). Screening mammography \& breast cancer mortality: Meta-analysis of quasiexperimental studies. PLoS ONE, 9(6). https://doi.org/10.1371/journal.pone.0098105.

Irvin, VL, Zhang Z, Simon MS, Chlebowski RT, Luoh SW, Shadyab AH, KrokSchoen JL, et al. (2020). Comparison of mortality among participants of women's health initiative trials with screening-detected breast cancers vs interval breast cancers. JAMA Network Open, 3(6), e207227. https://doi.org/10.1001/jamanetworkopen.20 20.7227.

Kementerian Kesehatan Republik Indonesia (2019). Hari kanker sedunia. Retrieved January 28, 2021, from https://www.kemkes.go.id/article/view/19020100003/hari-kanker-sedunia-2019.html.

Kementerian Kesehatan RI (2016). Bulan
Peduli Kanker Payudara (Breast Cancer Awareness Month). http://www.depkes.go.id/resources/download/pu sdatin/infodatin/InfoDatinBulanPedu liKankerPayudara_2016.pdf

Khatib MA (2006). Guidelines for the Early Detection and Screening of Breast Cancer.EMRO Technical Publications Series, 30.In WHO World Health Organization.

Løberg M, Lousdal ML, Bretthauer M, Kalager M (2015). Benefits and harms of mammography screening. Breast Cancer Research. 17(1): 1-12. https://doi.org/10.1186/s13058-015-0525$\mathrm{z}$.

Luczyńska E, Heinze S, Adamczyk A, Jrys J, Mitus Jw, Hendrick E. (2016). Comparison of the Mammography, Contrast-Enhanced Spectral Mammography and Ultrasonography in a Group of 116 patients. Anticancer Research August 2016, 36 (8) 43594366

Magnus MC, Ping M, Shen MM, Bourgeois J, Magnus JH (2011). Effectiveness of mammography screening in reducing breast cancer mortality in women aged 39-49 years: A meta-analysis. J Women's Health, 20(6): 845-852. https://doi.org/10.1089/jwh.2010.20 98.

Mehnati P, Tirtash M J. (2015). Comparative Efficacy of Four Imaging Instruments for Breast Cancer Screening. Asian Pacific Journal of Cancer Prevention. Asian Pacific Organization for Cancer Prevention, 16(15), pp. 6177-6186. doi: 10.7314/apjcp.2015.16.15.6177.

Murti B (2018). Prinsip dan Metode Riset Epidemiologi (5th ed.). Program Studi Ilmu Kesehatan Masyarakat, Program Pascasarjana, Universitas Sebelas Maret. 
Nickson C, Mason KE, English DR, Kavanagh AM (2012). Mammographic screening and breast cancer mortality: A case-control study and meta-analysis. Cancer Epidemiology Biomarkers and Prevention, 21(9): 1479-1488. https://doi.org/10.1158/1055-9965.EPI-12-0468

Rahimzadeh M, Baghestani AR, Gohari MR, Pourhoseingholi MA (2014). Estimation of the cure rate in Iranian breast cancer patients. Asian Pacific J Cancer Prev. 15(12): 4839-4842. https://doi.org/10.7314/APJCP.2014. 15.12.4839.

Richardson LC, Henley SJ, Miller JW, Massetti G, Thomas CC (2016). Patterns and trends in age-specific black-white differences in breast cancer incidence and mortality United States, 1999-2014. MMWR, 65(40): 1093-1098. https://doi.org/10.15585/mmwr.mm6540a1.

Riskesdas (2018). Hasil Utama Riset Kesehatan Dasar (RISKESDAS). Journal of Physics A: Mathematical and Theoretical, 44(8), 1-200. https://doi.org/10.1088/1751-8113/44/8/085201.

Taylor R, Morrell S, Estoesta J, Brassil A (2004). Mammography screening and breast cancer mortality in New South Wales, Australia. Cancer Causes and Control, 15(6): 543-550. https://doi.org/10.1023/B:CACO.0000036153.95 908.f2.
Weedon-Fekjræ H, Romundstad PR, Vatten LJ (2014). Modern mammography screening and breast cancer mortality: Population study. BMJ. 348: 1-8. https://doi.org/10.1136/bmj.g3701.

WHO (2016). Breast cancer: prevention and control. http://www.who.int/cancer/detection/breastcancer/en/.

WHO.(2014). WHO Position Paper on Mammography Screening.

Winters S, Martin C, Murphy D, Shokar NK (2017). Breast cancer epidemiology, prevention, and screening. In Progress in Molecular Biology and Translational Science (Vol. 151). Elsevier Inc. https://doi.org/10.1016/bs.pmbts.2017.07.002.

Yunus M, Ahmed N, Masroor I, Yaqoob J. Mammographic criteria for determining the diagnostic value of microcalcifications in the detection of early breast cancer. J Pak Med Assoc. 2004 Jan;54(1):24-9. PMID: 15058638.

Zeeshan M, Salam B, Khalid QSB, Alam S, Sayani R. Diagnostic Accuracy of Digital Mammography in the Detection of Breast Cancer. Cureus. 2018;10(4):e2448. Published 2018 Apr 8. doi:10.7759/cureus.2448 